\title{
Imaging of cerebral blood flow markers in Huntington's disease using single photon emission computed tomography
}

\author{
I C REID, ${ }^{*}$ J A O BESSON, ${ }^{*}$ P V BEST, $†$ P F SHARP, $\ddagger$ H G GEMMELL,$\ddagger$ \\ F W SMITH§
}

From the Departments of Mental Health,* Pathology, $\dagger$ Biomedical Physics, $\ddagger$ University of Aberdeen, and the Department of Nuclear Medicine, $\S A R I$, Foresterhill, Aberdeen, UK

SUMMARY Single photon emission computed tomography (SPECT) imaging of six Huntington's disease patients revealed a striking reduction in regional uptake of cerebral blood flow markers in vivo. Similar changes were found in one patient with "early stage" disease. The findings are compared with parallel magnetic resonance imaging (MRI) studies, and in one case, results of postmortem examination.

Huntington's disease is an inherited condition, characterised by continuous involuntary movements and slowly progressive dementia. Neuropathological studies reveal generalised cortical atrophy and gross atrophy of striatum and pallidum in advanced cases. ${ }^{1}$

The disease has been the subject of a number of studies using a variety of imaging techniques in recent years: these include pneumoencephalography, ${ }^{2}$ computed tomography, ${ }^{3} \mathrm{MRI}^{4}$ and positron emission tomography (PET). ${ }^{5}$ Although none of these techniques can provide diagnostically specific information, they have proved valuable adjuncts to studies of the pathophysiology of the condition. PET studies in particular have yielded useful information concerning the pattern of progression of metabolic alterations in the disease,${ }^{6}$ and in one report it is claimed that abnormalities can be detected in presymptomatic at risk individuals, ${ }^{7}$ although a recent study has failed to confirm this. ${ }^{8}$

In this study, we describe the use of single photon emission computed tomography (SPECT), using the radiopharmaceutical hexamethylpropyleneamineoxime (HMPAO) complexed with $99 \mathrm{~m}$ technetium. This material, when administered intravenously, is avidly taken up by brain tissue to an extent which is determined by cerebral blood flow. The uptake pat-

\footnotetext{
Address for reprint requests: $\operatorname{Dr} \mathrm{J}$ A O Besson, Department of Mental Health, University Medical Buildings, Foresterhill, Aberdeen AB9 2ZD.
}

Received 29 September 1987 and in revised form 2 February 1988. Accepted 2 April 1988. tern remains unchanged for at least 8 hours, allowing high quality tomographic images to be producedo using a rotating gamma camera interfaced to a com- $-\vec{\Phi}$ puter controlled data acquisition system. As regional cerebral blood flow (rCBF) imaging agent, HMPAO is simple to use, inexpensive and readilye available. ${ }^{9}$ In this respect, SPECT using ${ }^{99 \mathrm{~m}} \mathrm{TC}$ has considerable advantages over PET. ${ }^{10}$ Furthermore rotating gamma cameras are already available ina many nuclear medicine departments, obviating the need to purchase prohibitively expensive equipment to pursue such investigations.

The aims of the study were, firstly, to determine whether SPECT can detect CBF changes in the caudate nuclei of patients with established Huntington's disease, thereby further validating the use of this technique in the investigation of the dementing patient; and secondly, to examine the relationship between any detected blood flow abnormalities and the well documented caudate atrophy seen in this condition by comparing MRI findings in the same patients with the SPECT results. With this in mind, we took the opportunity to study one patient at risk for developing the disease who currently has equivocal, but suggestive symptomatology.

\section{Methods \\ Patient characteristics \\ Ten subjects were imaged initially: six patients with a case note diagnosis of Huntington's disease and documented family history, and four age matched normal control sub- jects. Ages ranged from 27 to 86 years (mean age 57 years).}


Table 1 Patient characteristics

\begin{tabular}{lllllll}
\hline $\begin{array}{l}\text { Patient } \\
\text { No. }\end{array}$ & $\begin{array}{l}\text { Family } \\
\text { history }\end{array}$ & $\begin{array}{l}\text { Movement } \\
\text { disorder }\end{array}$ & Psychosis & $\begin{array}{l}\text { Duration } \\
(y r)\end{array}$ & $\begin{array}{c}\text { Age } \\
(y r)\end{array}$ & Sex \\
\hline 1 & + & + & - & $8-10$ & 61 & F \\
2 & + & + & - & $6-7$ & 54 & F \\
3 & + & + & - & 7 & 40 & M \\
4 & + & + & + & 9 & 27 & F \\
5 & + & + & - & 12 & 74 & F \\
6 & + & + & - & 15 & 86 & M \\
7 & + & - & - & - & 35 & F \\
\hline
\end{tabular}

Of the six Huntington's patients, four were female, two were male. All had choreiform movement disorder and varying degrees of cognitive impairment, although formal cognitive testing was rendered impractical by the severe movement disorder and dysarthria experienced by most subjects. Mean time since diagnosis was 9 years, ranging from 6 to 15 years. All patients were taking neuroleptic medication at the time of study, and all but one were in-patients. Presence or absence of psychotic features in the history was also recorded (table 1, patients 1-6). One of the patients in the above group died shortly after the study and postmortem examination was performed.

The control subects showed no evidence of movement disorder or cognitive dysfunction, and had no personal or family history of neurological or psychiatric disorder. We also investigated one female patient, aged 35 years, "at risk" for Huntington's disease, her mother having been a sufferer. She initially presented to the psychiatric services following the death of her mother and was eventually considered to be suffering from a depressive illness. Psychological tests of cognitive function revealed no abnormality, and there was no firm evidence of movement disorder, although she had complained of increasing clumsiness (table 1, patient 7).

\section{Imaging techniques}

MRI: The Aberdeen Mark II imager was used, with a field strength of $0.08 \mathrm{~T}$ (resonance frequency of $3.4 \mathrm{MHz}$ ), employing an intercalated inversion recovery/saturation recovery pulse sequence with a TR of $1000 \mathrm{~ms}$ and a Tau of $200 \mathrm{~ms}^{11}$ The images examined were $T_{1}$ weighted, obtained by calculating the difference between saturation and inversion recovery sequences.

SPECT imaging: $800 \mathrm{mBq}$ of ${ }^{99 \mathrm{~m}} \mathrm{TC}$ labelled HMPAO was injected intravenously into resting subjects, and imaging carried out 15 minutes later using an IGE 400AT gamma camera digitally interfaced to a Link Analytical MAPS 5050 data acquisition system. The data were acquired on a $64 \times$ 64 matrix, pixel size $7 \mathrm{~mm} \times 7 \mathrm{~mm}$. The spatial resolution of this SPECT system is about $12 \mathrm{~mm}$.

Because acquisition is with a gamma camera a complete set of sections through the organ of interest is available after reconstruction. From each study a set of 12 images, each $7 \mathrm{~mm}$ apart and covering the brain from above the ventricles to the base of the cerebellum, was transferred to film. The sets of images from the six patients and four controls were mixed together and assessed blindly and independently by three of the authors (HGG, PFS and FWS). Caudate atrophy and ventricular dilation were then scored on a three point scale: $1=$ normal, $2=$ abnormal, $3=$ grossly abnormal).

\section{Results}

The results of the image ratings are shown in table 2 , and illustrated by figs 1 and 2 which both show single representative sections out of the 12 used for assessment. All scans, HMPAO and MRI, obtained from the group of patients with established disease were rated as abnormal, while those from the control group were rated as normal (control group not shown in table). Patient no. 1 had such gross movement disorder that satisfactory MRI images could not be obtained.

The scans from Patient no. 4 are illustrated by fig 1(a) (MRI) and fig 1(c) (HMPAO). Corresponding normal images are shown, for comparison purposes, in fig 1(b) and fig 1(d). The reduction in activity in the heads of the caudate nuclei can be clearly seen (arrows), and corresponding caudate atrophy is evident in the MRI image. The findings were confirmed postmortem in this patient: the brain weight was $1100 \mathrm{~g}$ and horizontal sectioning after fixation revealed symmetrical atrophy of the corpus striatum (fig 1(e)). Despite its considerably reduced size, however, the head of the caudate nucleus retained its medial convexity into the lateral ventricle. The anterior horn and body of each lateral ventricle were mildly enlarged. Histological examination revealed neuronal depletion in the corpus striatum accompanied by a relative increase in astrocytes. Gliosis and rarefaction were particularly prominent in the subependymal zone of the caudate nucleus. Such pathological features are typical of Huntington's disease.

The findings in Patient no. 7 are of particular interest; while the MRI scan was rated as normal with respect to caudate atrophy and ventricular dilatation, the HMPAO scan shows similar abnormalities to those found in the group of established sufferers (fig $1(a)$ and fig $2(b))$.

\section{Discussion}

Clearly, SPECT detects abnormalities in blood flow related uptake of radio-labelled HMPAO in structures critically involved in Huntington's disease, thus

Table 2 Image rating results from $H M P A O$ and $M R I$ scans (see text)

\begin{tabular}{llll}
\hline $\begin{array}{l}\text { Patient } \\
\text { No. }\end{array}$ & $\begin{array}{l}\text { HMPAO } \\
\text { (caudate } n \text {.) }\end{array}$ & $\begin{array}{l}\text { MRI } \\
\text { (caudate } n .)\end{array}$ & $\begin{array}{l}\text { MRI } \\
\text { (ventricular dilatation) }\end{array}$ \\
\hline 1 & 3 & - & - \\
2 & 3 & 2 & 3 \\
3 & 3 & 3 & 2 \\
4 & 2 & 2 & 2 \\
5 & 3 & 2 & 2 \\
6 & 2 & 2 & 2 \\
7 & 2 & 1 & 1
\end{tabular}



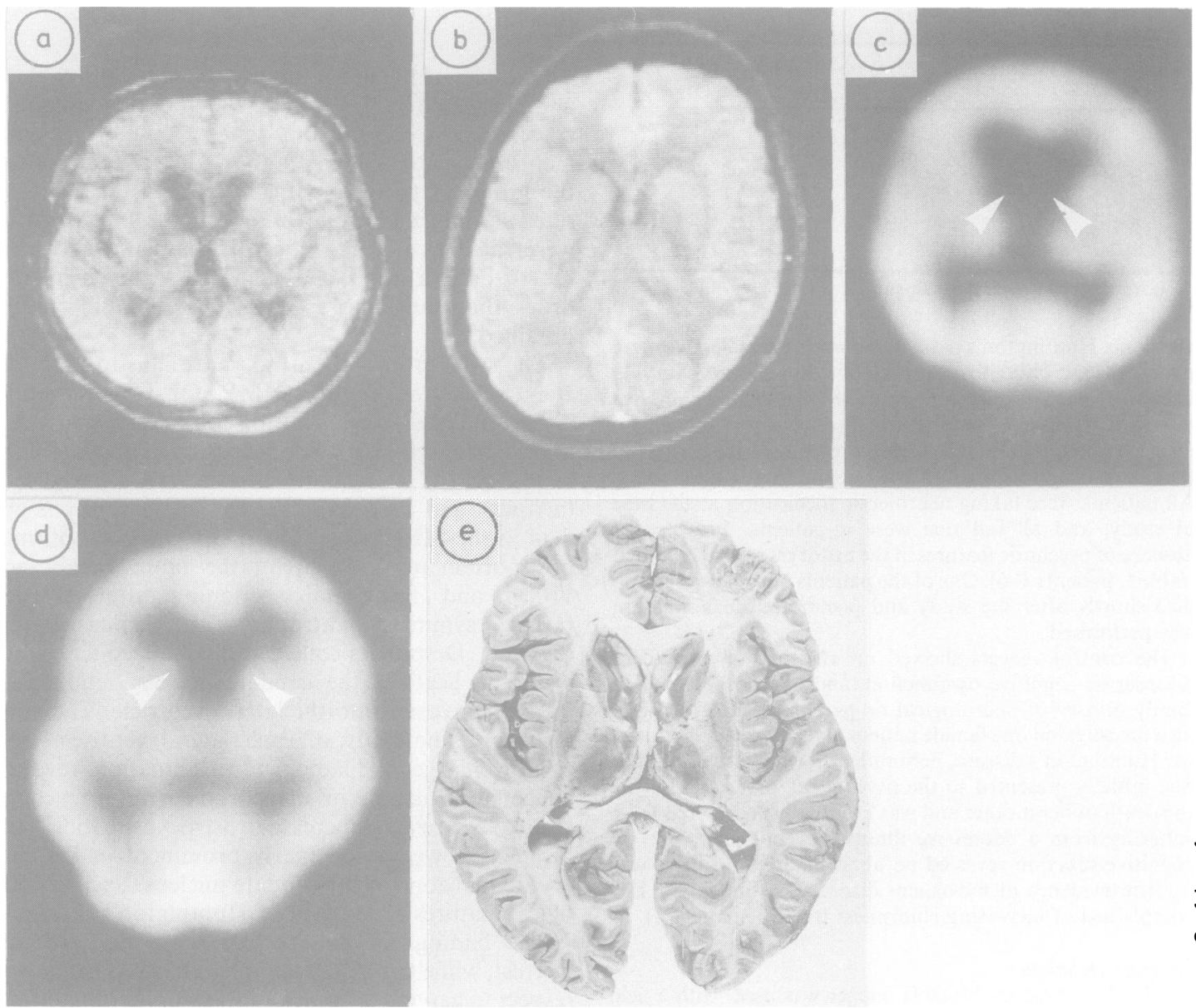

Fig 1 (a) MRI scan of a patient with Huntington's chorea; (b) MRI scan of a normal control subject; (c) HMPAO scan of a patient with Huntington's chorea; (d) HMPAO scan of a normal control subject; (e) Necropsy brain section of a patient with Huntington's chorea imaged (a) and (c).

extending the previously reported value of SPECT in the differential diagnosis of dementia. ${ }^{12}$ Furthermore, the appearances of the caudate nucleus are normal in patients with Alzheimer's disease, Parkinson's disease with or without dementia and in Gilles de la Tourette syndrome. ${ }^{13}$

It is likely that both structural and functional abnormalities contribute to the characteristic appearance of the caudate nuclei shown here, in view of the fact that the parallel MRI studies demonstrate that the caudate nuclei are significantly atrophied, a finding confirmed by post mortem examination of the brain of one subject. Such gross pathology is perhaps not surprising in view of the well established disease in our sample overall. However, studies of patients with "early" disease, or presymptomatic "at risk" individuals may reveal changes in rCBF, reflecting impaired caudate function, with little or no obvious atrophy. Metabolic alterations have already been reported in the caudate in the absence of structural change (as determined by CT scanning) using PET techniques. In this study we have shown rCBF changes in one patient who is at risk of developing the disorder. This patient cannot strictly be considered to be presymptomatic, in view of the fact that she has already presented to the psychiatric services, but the diagnosis on clinical grounds is by no means firmly established. It is of interest that the patient should present with affective symptoms alone. In view of the magnitude of the change seen on the SPECT images, it might be speculated that altered striatal function plays a more central role in production of psychiatric symptoms associated with Huntington's disease than previously considered. 

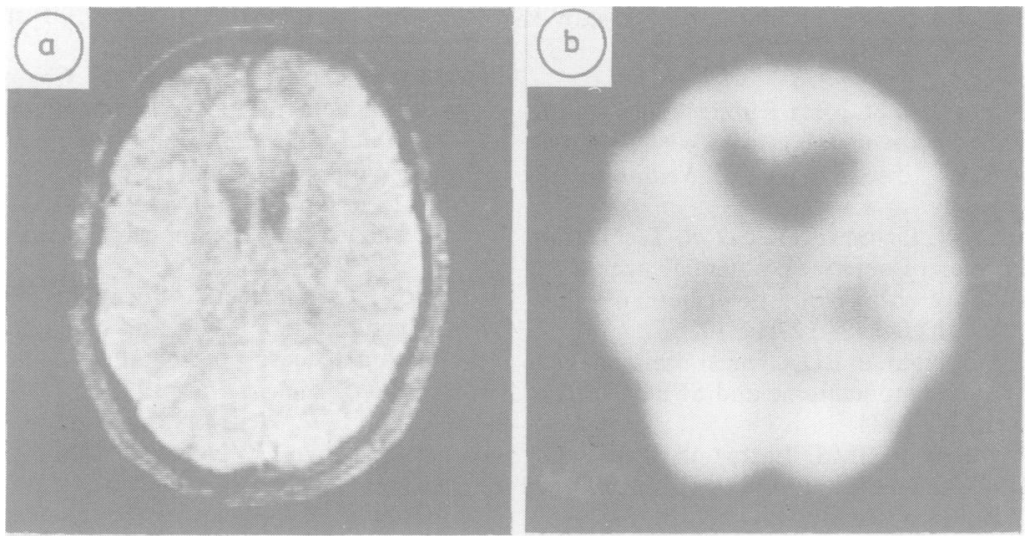

Fig 2 (a) MRI image of patient no. 7 with "early stage" Huntington's disease;

(b) HMPAO scan of patient (a).

The use of techniques measuring $\mathrm{rCBF}$ as an index of functional or metabolic integrity for clinical purposes must be approached with caution. Abnormalities in metabolism need not result in altered blood flow, as may occur, for example, in acutely infarcted tissue. ${ }^{14}$ Furthermore, the widely accepted belief that a close regional coupling between blood flow and tissue metabolic rate is dynamically maintained in normal brain has recently been challenged. Using multiple sequential administration of ${ }^{15} \mathrm{O}$-labelled radiotracers and PET, Fox and Raichle ${ }^{15}$ have shown that while the cerebral metabolic rate of oxygen is well correlated with measurements of cerebral blood flow in the resting state, regional uncoupling is found during neuronal activation induced by somatosensory stimulation. The relationship between $\mathrm{rCBF}$ and metabolism in pathological states is at present inadequately characterised and is likely to be complex; such considerations lie at the heart of studies concerned with the relative merits of SPECT and PET imaging.

It is worth noting that despite movement disorder of typical severity, all patients were successfully imaged using HMPAO, and in all but one, successful MRI images were obtained. This is in contrast to Bruyn and Went's prediction, ${ }^{16}$ that the long scanning time required would preclude the use of MRI in Huntington's disease because of the patients' inability to remain still. In addition, the imaging procedures, though lengthy, were extremely well tolerated by both patients and controls, suggesting that routine clinical use of this type of investigation in Huntington's disease is a practical reality.

As it has now become possible to distinguish, with reasonable certainty, some pre-symptomatic gene carriers of Huntington's disease from their unaffected siblings with the introduction of predictive testing using DNA probes, ${ }^{17}$ it is probable that more efficient studies of pre-symptomatic individuals using imaging techniques will be carried out. As a result, the principal value of such studies is likely to lie in disease staging and the valuation of change rather than simply diagnosis. If this technique is to be used to monitor the progress of Huntington's disease, it is clear that a more sensitive method of assessing the images must be used. This is a major problem in SPECT but a semi-quantitative index similar to one of those found useful in PET may prove to be suitable. ${ }^{7}$

We tentatively conclude, therefore, that SPECT may provide a widely available means of studying the progression of altered caudate function in Huntington's disease by following blood flow related abnormalities, thereby permitting detailed and widespread evaluation of any future therapeutic agent.

\section{References}

1 Lange H, Thorner G, Hopf A, Schroder KF. Morphometric studies of the neuropathologic changes in the choreatic diseases. J Neurol Sci 1976;28:401-25.

2 Gath I, Vinje B. Pneumoencephalographic findings in Huntington's Chorea. Neurology 1968;18;991-6.

3 Stober T, Wussow W, Schimrigk K. Bicaudate diameter - the most specific and simple CT parameter in the diagnosis of Huntington's Disease. Neuroradiology 1984;26:25-28.

4 Smith FW, Gemmell HG, Sharp PF, Besson JAO. ${ }^{99 m}$ TC HMPAO imaging in patients with basal ganglia disease. Br J Radiology 1988 (in press).

5 Kuhl DE, Markham CH, Metter EJ, Riege WH, Winter J. Cerebral metabolism and atrophy in Huntington's disease determined by ${ }^{18}$ FDG and computed tomographic scan. Ann Neurol 1982;12:425-34.

6 Kuhl DE, Markham CH, Metter EJ, Riege WH, Phelps ME, Mazziotta JC. Local cerebral glucose utilisation in symptomatic and pre-symptomatic Huntington's disease. In: Sokoloff L, ed. Brain Imaging and Brain Function (Sokoloff), New York, Raven Press, 1985, 199-209.

7 Mazziotta JC, Phelps ME, Pahl JJ. Reduced cerebral 
glucose metabolism in asymptomatic subjects at risk for Huntington's disease. $N$ Engl J Med 1987; 316:356-62.

8 Young AB, Penny JB, Starosta-Rubinstein S, et al. Normal caudate glucose metabolism in persons at risk for Huntington's disease. Arch Neurol 1987; 44:254-7.

9 Sharp PF, Smith FW, Gemmell HG, et al. Technetium ${ }^{99} \mathrm{~m}$ HMPAO stereoisomers as potential agents for imaging regional cerebral blood flow: human volunteer studies. J Nucl Med 1986;27:171-7.

10 Royal HD, Hill TC, Holman BL. Clinical brain imaging with isopropyl-iodoamphetamine and SPECT. Semin Nucl Med 1985;15:357-75.

11 Redpath TW, Hutchison JMS, Eastwood LM, et al. A low field NMR imager for clinical use. J Phys $E$ : Sci Instrum 1987;20:1228-34.

12 Gemmell HG, Sharp PF, Besson JAO, et al. Differential diagnosis in dementia using the cerebral blood flow agent ${ }^{99 m}$ HMPAO. A SPECT study. J Comp Assist Tomogr 1987;11:398-402.

13 Simmons JT, Pastakia B, Chase TN, Shults CN. Magnetic resonance imaging in Huntington's disease. Am J Neuroradiology 1986;7:25-8.

14 Ter-Pogossian MM, Herscovitch P. Radioactive oxygen15 in the study of cerebral blood flow, blood volume and oxygen metabolism. Semin Nucl Med 1985;15: 377-93.

15 Fox PT, Raichle ME. Focal physiological uncoupling of cerebral blood flow and oxidative metabolism during somatosensory stimulation in human subjects. Proc Natl Acad Sci USA 1986;83:1140-4.

16 Bruyn GW, Went LN. Huntington's chorea. In: Vinken PJ, Bruyn GW, Klawans HL, eds. Handbook of Clinical Neurology, 1986;5:267-313, Amsterdam, Elsevier.

17 Gusella JF, Wexler NS, Conneally PM et al. A polymorphic DNA marker genetically linked to Huntington's disease. Nature 1983;306:234-8.

\section{Neuromuscular transmission in the 17th century}

Jan Swammerdam (1637-1680) ${ }^{1}$ in the Netherlands was among the first to take an experimental approach to the problem of neuromuscular transmission. He demonstrated that the "animal spirits" which caused muscle contraction did not inflate the muscle as had been asserted by Galen since the first century AD and by Croone ${ }^{2}$ and Sylvius, Swammerdam's former teacher at Leyden.

In a posthumously published report ${ }^{3}$ he stated "a muscle at the time of its contraction, undergoes no inflation or tumefaction, from the afflux or effervescence of the supposed animal spirits; but that, on the contrary, it in this state becomes smaller, or collapses; or, to express my meaning more clearly, it takes up less room than before."

RT ROSS

\section{References}

1 Brazier Mary AB. A History of Neurophysiology in the 17th and 18th Centuries. From Concept to Experiment. New York, Raven Press, 1984:40.

2 Croone, William. De Ratione Motus Musculorum. London, Hayes, 1664.

3 From Floyd's translation of Biblia Naturae. London, 1758, quoted by Brazier. ${ }^{1}$

RT ROSS

\section{Annus mirabilis 1664}

"For scholars ... concerned with the workings of the brain, nerves and muscles, 1664 was an annus mirabilis. That year saw Steno's work on muscles and glands, Croone's anonymously written theory of muscle contraction, Willis' Cerebri Anatome, and the treatise that was to have the most lasting interest for all physiologists, philosophers, and psychologists: Traité de l'Homme, by Descartes."

RT ROSS

\section{Reference}

Brazier Mary AB. A History of Neurophysiology in the 17th and 18th Centuries. From Concept to Experiment, New York, Raven Press, 1984:18. 